\title{
Sachet Dosing Unit
}

National Cancer Institute

\section{Source}

National Cancer Institute. Sachet Dosing Unit. NCI Thesaurus. Code C71324.

A dosing unit equal to the amount of active ingredient(s) contained in a sachet. 